\title{
ANÁLISE DE MANIFESTAÇÕES PATOLOGICAS EM PATRIMÔNIO HISTÓRICO: UM ESTUDO DE CASO
}

\author{
MESSIAS, ANDRÉ \\ Estudante \\ UniFacema \\ Maranão; Brasil \\ andre_maiky@hotmail.com
}

\author{
SILVA, VALNEY \\ Físico \\ Instituição \\ Maranão; Brasil \\ valneymoura@yahoo.com.br
}

\author{
FARIAS, ANDRO \\ Eng. Civil \\ Instituição \\ Maranão; Brasil \\ androrian9@gmail.com
}

\author{
JESUS, ANA \\ Eng. Civil \\ Instituição \\ Maranão; Brasil \\ 96beatrizana96@gmail.com
}

\section{RESUMO}

As edificações são construídas para durarem décadas, resistindo aos mais diversos fatores de degradação. Algumas edificações já nascem com problemas patológicos, devido à erros de projeto ou execução. Outros problemas patológicos surgem ao longo dos anos, causados por erros de manutenção ou até mesmo a falta dela, somando esses fatores com fatores físicos, químicos e biológicos pode-se acarretar uma série de manifestações patologicas, diminuindo a sua vida útil, e consequentemente sua durabilidade. Esses fatores são bem mais desgastantes em edificações históricas, que já passaram por diversos eventos degradantes, sejam eles ocasionados por fatores naturais, como, variações de umidade, chuvas, ventos; fatores químicos como oxidação chuvas acidas; fatores biológicos como vegetação e animais. Desta maneira este artigo apresenta as manifestações patologicas identificadas em um edifício na cidade de Caxias - MA, por meio de inspeções visuais, de maneira que este estudo reforça a importância das inspeções prediais serem realizadas em edifícios históricos, permitindo que eles continuem a contar parte da história de um povo, mantendo os laços culturais antigos e atuais.

Palavras-chave: Inspeção predial. Manifestações patologicas. Edifícios históricos. Durabilidade.

\section{ABSTRACT}

The buildings are built to last for decades, resisting the most diverse degradation factors. Some buildings already born with pathological problems due to design or execution errors, in some cases both factors are present. Other pathological problems arise over the years, caused by maintenance errors, improper maintenance, or even lack thereof, adding these factors to physical, chemical and biological factors can lead to a series of pathological manifestations, decreasing their life usefulness, and consequently its durability. These factors are much more exhausting in historical buildings, which have already undergone several degrading events, whether caused by natural factors such as variations of humidity, rainfall, winds; chemical factors such as oxidation acid rain; biological factors such as vegetation and animals. In this way, this article presents the pathological manifestations that were identified in a building in the city of Caxias - MA, through visual inspections, so that this study reinforces the importance of building inspections in historic buildings, allowing them to continue tell part of the history of a people, maintaining the ancient and current cultural ties. KEYWORDS: Inspection building. Pathological manifestations. historic buildings. Durability.

\section{INTRODUÇÃO}

A história de um povo pode ser contada de várias formas, como por exemplo por meio de poesias, como a da canção do exilio do Escritor Gonçalves Dias. Além da poesia a cultura de um povo, em uma determinada época fica guardada em patrimônios edificadas, apresentando os costumes, técnicas construtivas, materiais utilizados e a arquitetura que predominava em uma época distante. As construções de valor histórico possuem grande relevância para as sociedades modernas, pois apresentam os valores culturais e detalhes do cotidiano dos antepassados, além de demonstrarem o desenvolvimento da humanidade ao longo dos anos. Conforme leite et al (2017), as gerações são capazes de vivenciar a história dos seus antepassados por meio dos patrimônios históricos ali existentes, que apresentam a cultura do lugar onde estão inseridos. 
A cidade de Caxias - MA é conhecida não apenas por ser berço de grandes poetas como o já mencionado Gonçalves Dias, Coelho Neto, Teófilo Dias, Vespasiano Ramos dentre outros nomes significativos para a cultura brasileira. Caxias - MA conta também com um marco na história, a revolta da balaiada, o que a torna uma cidade cheia de riqueza, contando ainda com obras arquitetônicas memoráveis, a exemplo o Palácio do Comendador Alderico Silva, o Palácio Episcopal, o Memorial da Balaiada, além do Instituto Histórico e Geográfico de Caxias (IHGC).

Diversos fatores estão ligados a origem de manifestações patologicas, assim como as causas que as fazem surgir, sejam erros de projeto, execução, erros de utilização e manutenção, ou até mesmo a falta de projeto e de manutenção, além da incompatibilidade de materiais, fatores naturais e imprevisíveis. Esses diversos fatores fazem com que ocorra a degradação da estrutura, o que acarreta a diminuição do seu desempenho e da sua vida útil, principalmente quando se trada de patrimônios históricos, que possuem décadas desde a sua construção até os dias atuais.

O prédio em questão foi construido por volta de 1915, servindo para atender as novas necessidades da epoca, já que as linhas ferreas estavam se prolongando, passavam por ali trens carqueiros e de passageiros, o predio faz parte do complexo ferroviario da cidade de Caxias-MA, essa edificação integrava a antiga Rede Ferroviaria Federal S.A (RFFSA). O predio da principal passou por algumas manutenções, e passou a ser ocupado pelo IHCG, voltando a coloborar significativamente para a cultura, economia e desenvolvimento social da região.

Conforme o boletim tecnico $\mathrm{n}^{\circ} 11$ da ALCOMPAT Brasil, o valor cultural de uma edificação está alem dos metodos consrutivos ou materiais utilizados, está também ligado com a idade da construção e ao seu papel de desenvolvimento de uma determinada sociedade. O que torna o predio da antiga estação ferroviario um importante patrimonio de historico.

A preservação desses bens tem um importante papel social e ambiental, pois com sua preservação economiza-se em matéria prima, energia e renova os valores culturais da população. Desta forma este estudo foi realizado no instituto histórico e geográfico de Caxias (IHGC), para realização do levantamento das manifestações patologicas presentes, por se tratar de um prédio histórico, as ações nele desenvolvidos para restauração ou manutenção, devem ser estudados por profissionais de várias áreas do conhecimento, de forma que o objetivo deste trabalho é a análise das anomalias presentes, servindo como material de consulta para o meio acadêmico e social por meio da pesquisa cientifica realizada.

\section{REFERENCIAL TEÓRICO}

\subsection{Cidade de caxias - ma}

Conforme descreve o livro cartografias invisíveis (2015), Caxias conta com uma arquitetura que apresenta o auge caxiense, conhecido como belle époque caxiense, onde os casarões com suas paredes grossas podem contar a história dessa cidade tão rica culturalmente e historicamente. Até o fim do século XIX a arquitetura que mais se encontrava era portuguesa, ao decorrer dos tempos novos estilos foram influenciando as construções, como os estilos neoclássico, eclético, neocolonial arte déco e o modernismo, desta forma Caxias conta com um rico acervo arquitetônico.

É a quinta maior cidade do estado do Maranhão, com uma população de estimada em aproximadamente 164.224 habitantes, densidade demográfica de 30,12 hab./ $\mathrm{km}^{2}$. A cidade ocupa ainda a terceira posição em área, que é de 5 $150,667 \mathrm{~km}^{2}$. É um dos maiores centros econômicos do estado graças a seu grande desempenho nos setores da indústria e um importante centro político, cultural e populacional do estado do Maranhão. (IBGE, 2018).

\subsection{Instituto histórico e geográfico de caxias - ma}

O IHGC é um órgão que preserva a história da cidade de Caxias - MA, ela abriga um valioso acervo cultural, não apenas de Caxias, mais também do estado do Maranhão, sendo referência para pesquisas da história e geografia do maranhão, atende toda a população local, do estado e até mesmo de outros estados, como por exemplo o estado do Piauí. O acervo da Biblioteca Maria das Mercês da Silva Lima conta com um acervo de aproximadamente 6.000 livros, entre enciclopédias, biografias, livros de romances e poesias, entre alguns livros raros. Situa-se no prédio Histórico da extinta estrada de ferro que tinha como rota São Luís - Teresina.

\subsection{Edificações históricas}


Segundo COELHO et al (2013), edificações históricas são compreendidas como um conjunto de bens de interesse para a memória de um município e de suas correntes culturais, englobando os patrimônios arquitetônicos, artísticos, bibliográficos, científicos, históricos entre outros. Ainda conceituando patrimônio histórico, CONSELHO INTERNACIONAL DE MONUMENTO E SITIOS (2001) apud LERSCH (2003), cita que patrimônio histórico pode ser entendido como um conjunto de bens com valor para a história da construção e das artes, ao qual foi constituído por peças e objetos explicativos de uma civilização em um certo momento.

A constituição federal de 1988 no artigo 216 se refere a essa mesma expressão como sendo patrimônio cultural brasileiro os bens de natureza material e imaterial, aos quais podem ser tomados de forma individual ou em conjunto, pontando em si, referências à identidade, à ação, à memória dos diferentes grupos que formaram a sociedade brasileira.

Assim podemos compreender que estudar e inspecionar essas construções históricas se faz necessário, de maneira a contribuir para a valoração e preservação da memória de uma sociedade passada, e contribuir para o desenvolvimento de técnicas de reabilitação, de forma a manter esses edifícios ativos, reduzindo a necessidades de novas construções (MESQUITA e PAUPÉRIO, 2015).

\section{Manutenção, durabilidade e vida útil}

Manutenção conforme a NBR 15575-1 de 2013 são atividades realizadas durante a vida total da obra, tendo como finalidade garantir um desempenho satisfatório de forma que conserve ou recupere a estrutura, mantendo a segurança e atendendo as necessidades do usuário.Gomide et al (2005), define no manual de elaboração de projetos de preservação do patrimônio cultural que manutenção é o conjunto de operações realizadas para garantir um bom funcionamento e operação da edificação, em seus sistemas elétricos, hidro sanitários, e outras inspeções que se façam necessárias.

Durabilidade pode ser caracterizada pela capacidade da edificação e dos sistemas que a compõem de desempenhar as suas funções levando em consideração as manutenções previstas durante a sua vida útil, conforme expressa a NBR 15575/2013. Para Medeiro et al (2011), a durabilidade é todo o conjunto de interações que acontecem na estrutura, não apenas internamente, mas também externamente a ela, de forma que cada parte da estrutura, pode obedecer a uma durabilidade diferente de outras partes, portanto a durabilidade não é um conceito que possa ser considerado homogêneo para todas as partes de uma edificação.

Vida útil é entendido como sendo um período de tempo, em que um edifício ou as suas partes constituintes se mantem realizando os serviços para os quais foram projetados e executados, levando em consideração as manutenções que devem ser realizadas de forma periódica, atentando-se que diversos fatores influenciam na vida útil de uma estrutura, como o meio a qual está inserida, a qualidade dos materiais e da execução da edificação como um todo, as limpezas e manutenções, assim como fatores climáticos, dentre outros que possam interferir na durabilidade das partes que constituem uma edificação (NBR 15575-1, 2013).

\section{1. origem das anomalias}

Para Helene (1992), uma obra pode ser dividida em cinco etapas primordiais, planejamento, projeto, fabricação de materiais e componentes fora do canteiro de obra, execução e por fim o uso, de forma que as manifestações só começam a aparecer na fase de execução, e em sua maioria na fase de uso, que é a mais longa das etapas. Ainda segundo o referido autor, para que um diagnóstico seja eficaz é necessária a identificação do processo ao qual deu origem a anomalia.

As manifestações patológicas para Valente et al (2009), tem sua origem correlacionada a fatores como mal planejamento de projeto e execução, na falta de manutenção ou uso diferente daquele para o qual a edificação foi projetada, de forma que em um dado momento as manifestações patológicas irão surgir.

\subsection{Causas das anomalias}

As edificações de valor cultural que constituem o patrimônio construído sofrem degradações nos seus componentes e sistemas construtivos em decorrência dos mais diversos motivos. Alguns desses motivos é o tempo, o intemperismo, as formas de utilização da edificação e do meio acarretam alterações das propriedades físicas e químicas dos materiais o que compromete o desempenho dos elementos construtivos e a funcionalidade da edificação (FERREIRA, 2010). Para 
a NBR 6118/2014 os mecanismos que podem atuar de forma a deteriorar a estrutura podem ser dos mais diversos, como ações mecânicas, ações cíclicas, retração, fluência, movimentações térmicas, além de outros possíveis agentes que causem algum problema para a estrutura.

Consoante Helene (1992), os mecanismos causadores da deterioração de uma estrutura são dos mais diversos, podendo eles serem físicos, químicos, biológicos, incompatibilidade de materiais além de ações humanas e desastres naturais. Esses mecanismos ocorrem muitas vezes de forma conjunta, acelerando assim o processo de deterioração, ocasionando em manifestações patológicas.

De acordo com Silva e Jonov (2011), as causas das manifestações patologicas podem ser diversos, alguns deles estão descritos na tabela a seguir:

Cargas;

Tabela 2: Causas das Manifestações patologicas.

Variação de umidade;
Variações térmicas internas e externas do concreto;
Agentes biológicos, químicos e físicos;
Incompatibilidade de Materiais;
Agentes atmosféricos.

Fonte: Adaptada de Silva e Jonov (2011).

\section{3. CONCRETO}

Segundo Bertolini (2010), o concreto assim como os tijolos possuem uma estrutura cheia de vazios, o que propicia a entrada de agentes de degradação. Através desses poros é possível que ocorra a entrada de substâncias liquidas e gasosas provocando uma série de mudanças nos materiais. Conforme a NBR6118/2014 alguns dos elementos que aceleram a degradação do concreto são:

Lixiviação é o mecanismo físico-químico responsável por dissolver e carregar os compostos hidratados da pasta de cimento por ação de águas puras, carbônicas agressivas, ácidas e outras;

Expansão por sulfato é a expansão por ação de águas ou solos que contenham ou estejam contaminados com sulfatos, dando origem a reações expansivas e deletérias com a pasta de cimento hidratado;

Reação álcali-agregado é a expansão por ação das reações que ocorrem entre os álcalis do concreto e os agregados reativos, ocorrendo em um processo simultâneo ao entrarem em contato com a água.

Ainda de acordo com a NBR 6118/2014, as fissuras são inevitáveis em elementos estruturais, um dos motivos é a baixa resistência a tração dos concretos, assim o projetista da estrutura deve procurar meios de controlar a fissuração, de modo a proteger a armadura quanto corrosões, e garantir a aceitabilidade aos usuários da edificação. Essas fissuras podem ocorrer devido a cargas acima nos elementos estruturais, que ultrapassam o limite de projeto, as fissuras também ocorrem por conta de retração térmica, relacionado com as reações químicas do concreto, de forma que é possível fazer o controle por meios tecnológicos e principalmente na definição do traço utilizado e na cura do concreto.

Sousa e Ripper (1998), explicam que as fissuras são os defeitos mais característicos do concreto, já que o concreto resiste pouco a trações, de modo que esse tipo de danos são muito característicos de estruturas de concreto, e logo chama a atenção dos usuários, quando são muito acentuadas, pois apresenta uma característica fora do normal para a estrutura. É importante relatar que as fissuras nem sempre apresentam caráter de defeito estrutural, pois podem ter várias origens, magnitudes e intensidades diferentes, além disso é necessário que se analise a progressão, a profundidade e a extensão ao longo do tempo.

\subsection{AÇO}


De acordo com Sousa e Ripper (1998) e a NBR 6118/2014, os principais agentes de deterioração das armaduras são:

Despassivação por carbonatação, que é ocasionada pela entrada do gás carbônicos provenientes da atmosfera, sobre o aço das armaduras. Esse problema ocorre principalmente devido a porosidade do concreto, que permite a entrada de agentes para seu interior, que nesse caso é o gás carbônico, que atinge a armadura e quebra a proteção de óxido que há protege, chamada de película óxida passivante, ocorrendo então corrosão da armadura.

Despassivação por ação de cloretos, é definida pela ruptura local da camada de passivação, ocorre por meio do alto teor de íon cloro. Esses agentes ocorrem de forma parecida ao ocasionado por carbonatação, de forma que os agentes penetram o concreto por meio dos poros, no entanto é necessário que ocorra diferença de potencial na armadura, umidade, oxigênio e a presença dos cloretos, o que dará início a corrosão do aço.

\subsection{MADEIRA}

O emprego da madeira na construção está relacionado com a origem de edificar, a lignina e a celulose, principais constituintes da madeira, lhe conferem boa resistência mecânica no mesmo sentindo que atuam as fibras, sendo a madeira muito resistente tendo um peso relativamente baixo. quando não tratadas ou tratadas de forma inadequada e não conservadas, poderão ocorrer problemas anômalos ocasionados por fatores físico-químicos, degradações biológicas, e degradação de origens estruturais. Resiste bem a tração e compressão, além de ser flexível, pode ser cortada e moldada de inúmeras formas. (RODRIGUES E SALES, 2013). Na tabela 1, são apresentados os principais agentes de deterioração da madeira.

Tabela 1: Principais agentes de deterioração.

\begin{tabular}{l|l} 
Bióticos & Abióticos \\
\hline Bactérias & Agentes Físicos \\
\hline Fungos & Agentes químicos \\
\hline Insetos & Agentes atmosféricos \\
\hline Perfuradores marinhos & Danos devido ao fogo \\
\hline
\end{tabular}

Fonte: Brito (2014).

Esses agentes atuam diretamente nas madeiras, diminuindo consideravelmente a suas características, por tanto é necessário que se faça a proteção de forma adequada, já que mesmo utilizando produtos e/ou técnicas para a proteção de madeiras contra ataques biológicos, com o passar do tempo alguns produtos perdem sua capacidade de proteção, necessitando de reparos ou manutenções, além de que pode ocorrer ainda erros de leitura de projeto, dimensionamento errado, má execução, e outras formas de degradação da madeira (BRITO, 2014).

\section{MATERIAIS E MÉTODOS}

Realizou-se uma pesquisa exploratória para ter uma compreensão maior do objeto de estudo e aprimoramento das ideias, desta forma foi possível conhecer melhor o objeto que foi estudado e outros métodos. De acordo com Gil (2007), esse método facilita a familiaridadecom o objeto a ser estudado, de forma flexível para a consideração de aspectos importantes ao estudo.

Para a fundamentação teórica foi utilizado a pesquisa bibliográfica, onde foi levantado dados de autores já conhecidos e que possuíam uma grande relevância no meio científico e acadêmico nessa área de estudo. Para Ribas e Fonseca (2008), a pesquisa bibliográfica é aquela que abrange toda a teoria a qual já passou por um tratamento científico, e foi publicado e divulgada em diversos meios.

Este estudo utilizou também a pesquisa descritiva para descrever as características dos fenômenos patológicos, assim com a sua ligação com suas possíveis origens. Gil (2007), cita em seu livro que a pesquisa descritiva tem como objetivo fundamental, descrever as características de uma população ou fenômenos, e/ou ainda realizar a relações entre variáveis. Desta maneira foi necessário a realização de visitas ao edifício que passou por inspeção, para o levantamento das manifestações patologicas que estariam atuando sobre à mesma. Para o Instituto de Engenharia (2016), nas vistorias e inspeções são verificados aspectos sintomatológicos, onde prevalece as análises visuais no desenvolvimento dos trabalhos diagnósticos. 
Conforme Helene et al (2016), inspeção visual é utilizada para avaliar a estrutura e determinar os locais em que os problemas podem ser identificados de forma visual, sendo o registro fotográfico essencial nesta etapa do levantamento dos dados.

Essas visitas se caracterizam como uma pesquisa de campo, para Ribas e Fonseca (2008), pesquisa de campo consiste na observação dos fatos e fenômenos que ocorrem de forma natural, na qual essa pesquisa tem como objetivo, a coleta de dados e informações em relação aos problemas, para que se possa buscar respostas.

$\mathrm{O}$ estudo de caso se deu pelo fato de buscar dados mais aprofundados sobres as anomalias que existiam no prédio do IHCG. Para Gil (2007), o estudo de caso é definido pelo estudo profundo e exaustivo, de poucos objetos de estudo, permitindo um conhecimento amplo sobre o objeto estudado.

Para o tratamento dos dados utilizou-se da variável qualitativas. Para Fachin (2006), variável qualitativa além de relacionar aspectos mensuráveis, também os faz descritivamente.

\section{RESULTADOS E DISCUSSÃO}

\subsection{Manifestações patologicas encontradas}

$\mathrm{Na}$ vistoria realizada, foi possível detectar as manifestações patologicas mais presentes na edificação do IHCG, essas manifestações atuam de forma a degradar mais rapidamente a estrutura do prédio, além de causar problemas estéticos a edificação. O IHCG passou por uma reforma recente, dessa forma não deveria apresentar tantas manifestações. As manifestações presentes na fachada, são mais estéticos que estruturais, como se pode perceber nas imagens a seguir:

Figura 1: Fissura na pintura e sujidade.

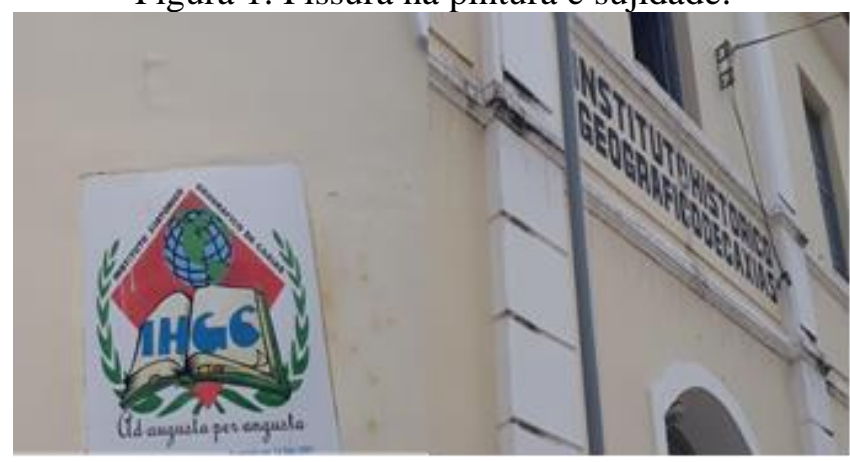

Fonte: Autor (2019)

Como se percebe ocorre problemas na pintura, são fissuras que podem ter ocorrido por erros na execução, e algumas manchas, aparentemente causadas por agentes de poluição que são transportados pelo vento, e pelas águas das chuvas.

\subsection{Eflorescência e deterioração da pintura.}

Para Vitorio (2003), a eflorescência pode se apresentar em qualquer elemento de concreto, além de alvenarias e argamassas, sendo definida como a sedimentação de sais sobre a superfície, geralmente podem ser sais de metais alcalinos, como sódio e potássio, e alcalino ferroso cálcio e magnésio, podendo tais sais serem bastante agressivos de forma a deteriorar as alvenarias e argamassas.

Figura 2: Eflorescência e deterioração da pintura. 


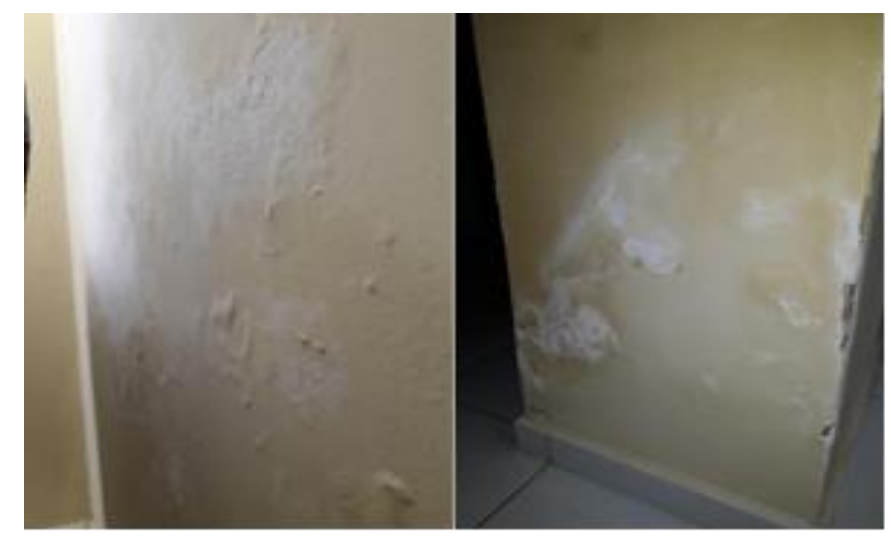

Fonte: Autor (2019)

A eflorescência é a aparição de formações salinas na superfície dos materiais geralmente de coloração esbranquiçada, ocorre em geral devido a evaporação da água, ou ainda quando a pintura é realizada diretamente em locais que apresentem umidade.

É possível também perceber a deterioração da pintura, não apenas por meio da eflorescência na parede, mas também por meio de choques mecânicos de objetos contra a parede, o que pode facilitar a penetração de umidade no revestimento, devido a exposição direta da argamassa.

\subsection{Bolor}

O bolor é ocasionado a partir de fungos filamentosos, que provocam biodeterioração nas estruturas, dessa forma é possível notar sua presença por meio de manchas. Esse processo ocorre a partir da liberação de pigmentos ou micélio, que forma o conjunto de hifas, sendo essa última a unidade filamentosa dos fungos (Guerra et al 2012).

Figura 3: Bolor devido umidade e dejetos de pombos.

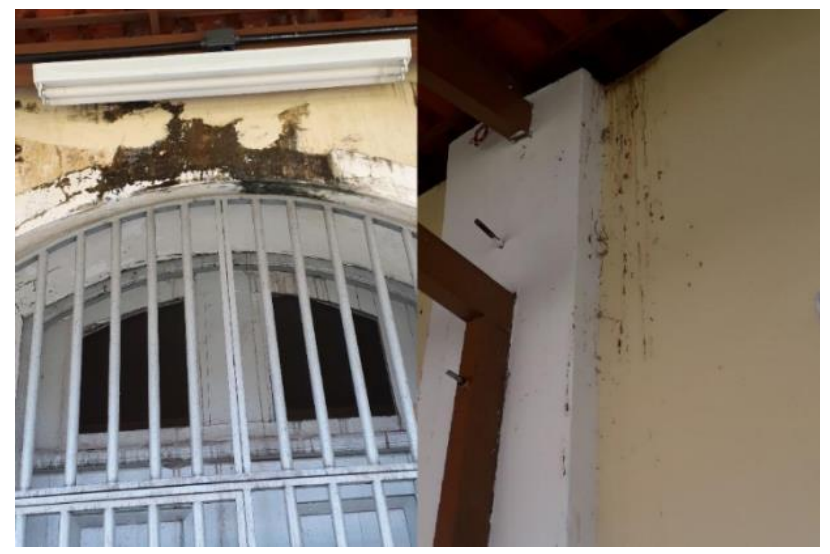

Fonte: Autor (2019).

A presença de bolor existente fica na parte externa da edificação, nesse local foram encontrados dejetos de pombos e muita umidade, ocasionada por uma infiltração, o que possibilita a proliferação de fungos, essa anomalia possivelmente está ligada a falha de manutenção, já que a infiltração ocorreu após uma manutenção realizada no prédio, ou ainda devido ao emprego de materiais de baixa qualidade, ou a mão de obra desqualificada.

\subsection{Fissuras e infiltração}

De acordo com Almeida (2017), as fissuras podem indicar perigo para a estrutura caso se desenvolvam a partir de elementos estruturais, caso não sejam desenvolvidos em elementos estruturais, podem ainda comprometer o desempenho da edificação, como estanqueidade à água, a durabilidade, a insolação, a acústica entre outros, podendo ainda trazer problemas psicológico aos usuários. 
É possível perceber que existem fissuras no pilar e próximo ao pilar, além das fissuras existe também muita sujidade, provenientes de poluição atmosférica que é depositado nos telhados e microrganismos, quando essa sujidade em contado com as águas das chuvas escorrem pelo revestimento e ficam depositados ali. Na outra imagem é possível perceber a infiltração existente devido as fissuras na parte exterior do edifício, e a porosidade existente no material, essa manifestação fica localizada na parte externa e interna do auditório, Além da umidade de infiltração na parte interna do auditório, também é possível perceber irregularidades devido o mal nivelamento do piso, sendo que o auditório passou por uma manutenção.

Figura 4: Bolor devido umidade e dejetos de pombos.

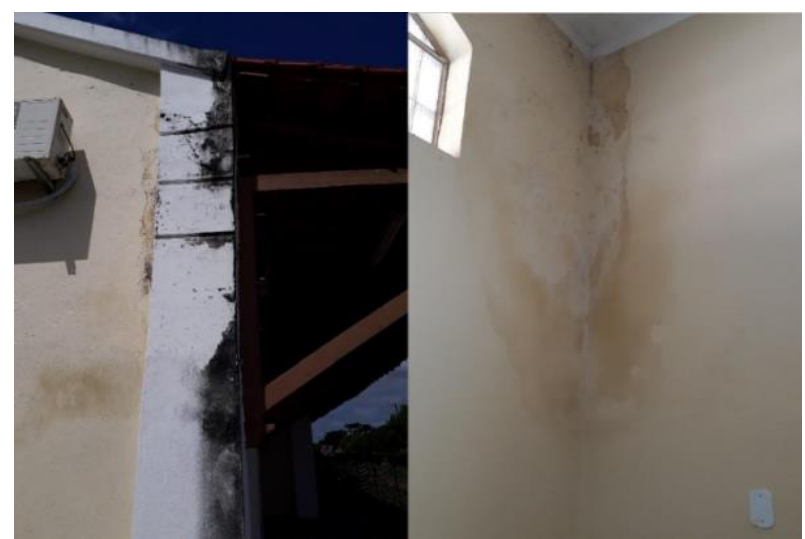

Fonte: Autor (2019).

Essa fissuras no pilar pode ter ocorrido depois da reforma da cobertura da área externa, que antes contava com telhas Brasilit e agora está sendo usada telhas cerâmicas, é possível que tenha sido mal dimensionado as cargas, já que falamos de um edifício histórico, e com a penetração de água outras anomalias vão surgindo na estrutura.

\subsection{Formigas}

Figura 6: Ataque de formigas à estrutura.

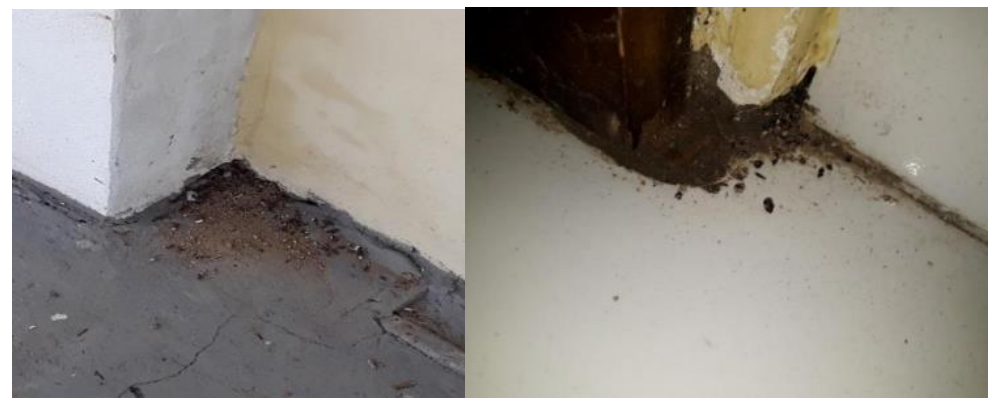

Fonte: Autor (2019).

Além dos cupins e carunchos também é possível encontrar formigas por todo o prédio, elas escavam buracos próximo a pilares, afofando assim o solo ao redor dos elementos estruturais o que pode acarretar outros possíveis danos a estrutura. Para Sousa e Ripper (1998), as formigas afofam a terra próximo a elementos de fundação, provocando recalques diferenciais, levando a sérios problemas para a estrutura, o que acarreta trabalhos de recuperação bem dispendiosos. Caso esse problema não seja sanado de forma eficaz o quanto antes, danos mais graves podem acontecer a estrutura, ocasionando mais gastos para a recuperação.

\subsection{Agentes xilófagos}


Figura 7: Cupins na estrutura de madeira do telhado e no forro de madeira.

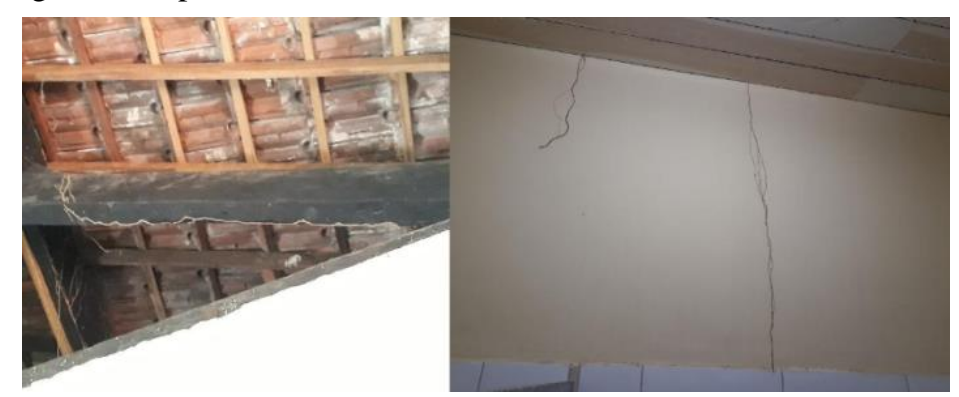

Fonte: Autor (2019)

É possível perceber a presença de insetos xilófagos como cupins e carunchos, mesmo já tendo passado por reformas e por tratamentos contra o ataque dos insetos, ainda existem muitos focos. Para Sousa e Ripper (1998), os cupins atacam primeiramente as estruturas de madeira, como portas, janelas e as madeiras do telhado, e destroem os tijolos para construírem os cupinzeiros, provocando fissuras nas estruturas.

Por esse motivo é de fácil detecção que as medidas tomadas não foram de muita serventia, pois os insetos continuam a acelerar a degradação do edifício comprometendo a segurança, estética, utilidade e habitabilidade.

\subsection{Oxidação e problemas de estanqueidade}

Figura 9: Oxidação da calha e problemas de estanqueidade.

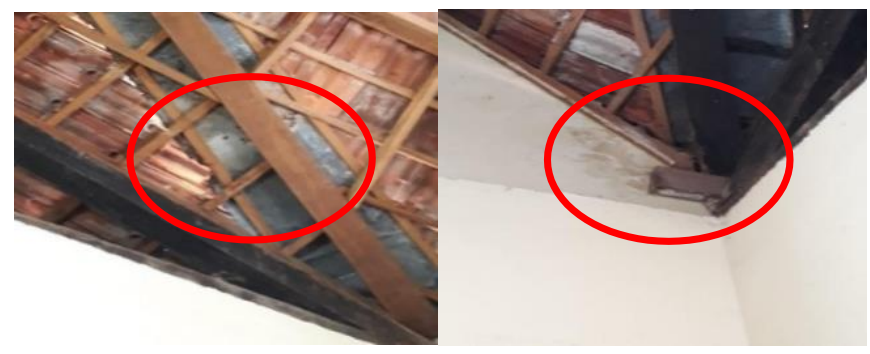

Fonte: Autor (2019).

É possível perceber que a calha do telhado apresenta anomalias na sua estrutura, em algumas partes é possível perceber a corrosão e em outras a oxidação do material, o que facilita a entrada de água para a estrutura de madeira do telhado, ou não foi removido para a colocação de um novo, com isso a umidade provocada pelas aguas da chuva estão atuando no processo de degradação da madeira e da argamassa. Na imagem é possível perceber umidade na parede próximo a ligação das águas do telhado, que não foram bem projetados, ou foram mal executados, permitindo a passagem de água para o interior da edificação, além do material que já está bem degradado.

\subsection{Deterioração do piso}

O estado do piso na parte externa da edificação apresenta uma grande quantidade de umidade, o que está ocasionando presença de microrganismo no piso, além do bolor é possível perceber muitas fissuras no piso, em algumas partes é possível ver que a pintura que foi colocada para evitar a penetração da água está saindo, permitindo que ocorra a infiltração de aguas se instale, o que ocasiona o aumento das fissuras devido a água que penetra no piso. Na parte interior do prédio nota-se a ruptura e a falta de partes das cerâmicas, isso pode ocorrer por choques mecânicos, produtos utilizados para fazer a limpeza que acaba acelerando a deterioração, envelhecimento natural. 
Figura 10: Fissuras e microrganismos na parte externa e ladrilhos hidraúlicos deteriorados

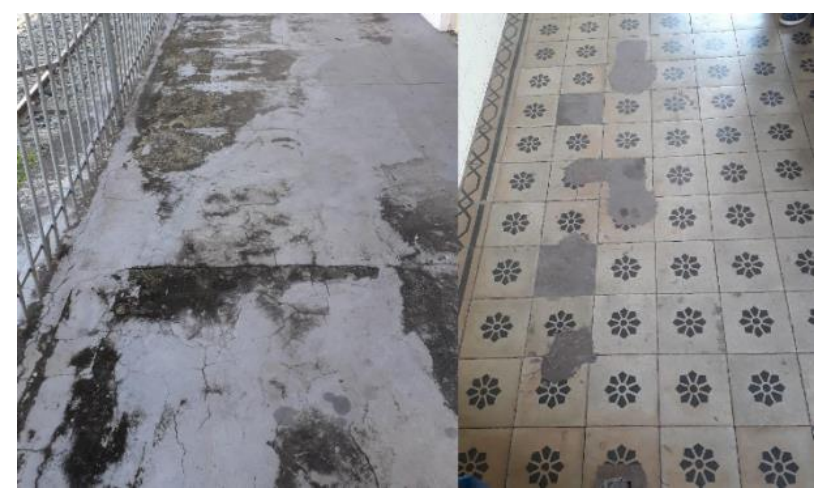

Fonte: Autor (2019).

\section{CONCLUSÕES}

As construções históricas quando não recebem inspeções e manutenções adequadas, vão se deteriorando mais rapidamente, por possuírem uma certa idade de exposição a diversos agentes de degradação, sejam eles intrínsecos, ou extrínsecos a estrutura, além da degradação natural dos materiais, alguns mais rapidamente que outros.

A umidade nas construções pode ser considerada uma das mais difíceis manifestações patológicas de resolver, devido á grande quantidade de variáveis possíveis para ocasionar umidade na estrutura, pois ela pode surgir de infiltrações decorrentes de água das chuvas, de vazamentos nas redes de distribuição de água, do lençol freático, pode aparecer na estrutura por meio de capilaridade, por meio da condensação dentre outras formas.

No IHGC foi possível detectar que os maiores problemas são relacionados a presença indesejada da água, ocasionada por infiltração de água das chuvas, umidade ocasionada por capilaridade, por defeitos hidro sanitários devido materiais de má qualidade, ou mão de obra deficiente, de forma que mesmo recebendo manutenções, ainda apresenta muitos defeitos. Outro problema que se apresentou de forma frequente e por todas as partes do prédio foram os cupins, que podem provocar muitos danos a estrutura, seja deteriorando as estruturas de madeira, seja agindo sobre os tijolos para fazerem os cupinzeiros, ocasionando fissuras. Um agente que pode provocar danos graves a estrutura são as formigas, que escavam próximos aos elementos estruturais, o que foi possível perceber buracos próximos as estruturas.

Para que se possa tomar medidas terapêuticas é necessário que se realize exames mais detalhados, e aprofundados, de forma a escolher a melhor prescrição para a estrutura, por se tratar de uma edificação histórica é preciso que a estrutura passe por um grupo multidisciplinar, para que se possa chegar a um diagnóstico mais preciso, e se obtenha uma manutenção satisfatória e de qualidade.

\section{REFERÊNCIAS}

ABNT NBR 6023 - Informação, documentação, Referências e Elaboração. Rio de Janeiro, p. 68. 2018.

ABNT NBR 5674 - Manutenção de edificações, Requisitos para o sistema de gestão de manutenção. Rio de Janeiro, p. 252012.

ABNT NBR 6118 - Projeto de Estruturas de Concreto, Procedimentos. Rio de Janeiro, p. 238. 2014.

ABNT NBR 15575 - Edificações habitacionais - desempenho parte 1. Rio de janeiro, p. 602013

ACADEMIA CAXIENSE DE LETRAS. Cartografias invisíveis. $1^{\text {a }}$ ed. Caxias, MA Academia caxiense de letras, 2015.

ALMEIDA, R.S. Patologia na construção civil. $13^{\mathrm{a}}$ ed. Goiânia. Revista Especialize On-line IPOG. $\mathrm{n}^{\circ} 013$ Vol.01/2017. jul/2017.

BRASIL. ARTIGO 216 DE05 DE OUTUBRO DE 1998. Cultura. Brasília, DF, dez. 2017. 
Disponívelem:<https://www.senado.leg.br/atividade/const/con1988/con1988_14.12.2017/art_216-A_.asp>. Acessado em 13 de out. 2018.

BRITO, L. D. Patologia em estruturas de madeira: metodologia de inspeção e técnicas de reabilitação. Tese (Doutorado) - Escola de Engenharia de São Carlos, Universidade de São Paulo, São Carlos, 2014.

BERTOLINI, L. Materiais de construção, prevenção. Tradução Leda Maria Marques Dias Beck - São Paulo: Oficina de Textos, 2010.

COELHO, F. C. A; CARNEIRO, M.D. Incidência de manifestações patologicas em edificações históricas de Sobral - CE. João Pessoa, PB. Anais do IX Congresso internacional sobre patologia e recuperação de estruturas. CINPAR, 2013.

DEUTSCH, S. F. Perícias de engenharia: a apuração dos fatos. $3^{\circ}$ ed. São Paulo: Liv. e Ed. Universitária de direito, 2016.

FACHIN, O. Metodologia. $5^{\circ}$ ed. São Paulo: Saraiva, 2006

FERREIRA, J.A.A. Técnica de diagnóstico de patologia em edifícios.2010.126f. Dissertação (Mestrado em engenharia civil) - Faculdade de Engenharia da Universidade do Porto. Portugal.

GIESBRECHT, R. M. Estações Ferroviárias do Brasil Disponível em: < www.estacoesferroviarias.com.br/mapi/caxias.htm >. Acesso em: 27 fev. 2020.

GIL, A. C. Como elaborar projetos de pesquisa. 4. ed. São Paulo: Atlas, 2007.

GOMIDE, J. H; SILVA, P.R; BRAGA, S. M. N. Manual de elaboração de projetos de preservação do patrimônio cultural. Vol. 1. Brasília, 2005.

GUERRA, F. L; CUNHA, E. G; SILVA, A.C.S. B; KNOPY, S. Análises das condições favoráveis á formação de bolor em edificação histórica de pelotas, RS, Brasil. Ambiente Construído, Porto Alegre, v. 12, n. 4, p. 7-23, out./dez. 2012. ISSN 1678-8621.

HELENE, P. Manual para Reparo, reforço e proteção de estruturas de concreto. 2º ed. São Paulo: PINI, 1992.

HELENE, P; COUTO, D; MIRANDA, D; PACHECO, J. Retrofit da estrutura de concreto armado de um edifício em são paulo com mais de 50 anos de idade. Revista IBRACON Concreto \& Construções, Ano XLIV, Nº82, AbrJun 2016, p. 49-57.

IBGE. INSTITUTO BRASILEIRO DE GEOGRAFIA E ESTATISTICA. Cidades ibge.

Disponível em: <https://cidades.ibge.gov.br/brasil/ma/caxias/panorama>. Acesso em: 23 set. 2018.

INSTITUTO DE ENGENHARIA. Diretrizes técnicas de engenharia diagnóstica em edificações. São Paulo, SP.: LEUD, 2016.

ISO 13823:2008 - General principles on the design of structures for durability. Disponível em:< https://www.iso.org/obp/ui/\#iso:std:iso:13823:ed-1:v1:en>. Acessado em 05 de abr. de 2019.

LEITE, F; SILVA, D; CORDEIRO, M. Manifestações patológicas nas fachadas de igrejas do centro do RecifePE. Pernambuco: Ed. Conpar, 2017

LERSCH, I. M. Contribuição para a identificação dos principais fatores de degradação em edificações do patrimônio cultural de porto alegre. Dissertação (Mestrado engenharia civil) - Universidade Federal do Rio Grande do Sul. Porto Alegre - RS, 2013.

MAZER, W. Patologia, recuperação e reforço de estruturas de concreto. Universidade Tecnológica do Paraná. Curitiba, 2008. Disponível em: <https://docplayer.com.br/19756100- Patologia-recuperacao-e-reforco-de-estruturasde-concreto.html>. Acessado em: 22 de fev. 
2019.

MEDEIROS, M. H. F; ANDRADE, J. J. O; HELENE, P. Durabilidade e Vida Útil das Estruturas de Concreto. Concreto: Ciências e Tecnologia. IBRACON 2011. Cap. 22. Pags.37. Disponível em: <http://www.phd.eng.br/wp-content/uploads/2014/07/lc55.pdf> Acessado em: 05 de abr. 2019.

MESQUITA, E; PAUPÉRIO, E; ARÊDE, A; VARUM, H. Caracterização, avaliação e recuperação estrutural de construções históricas. Mérida-México. ALCONPAT Brasil. n. 11. dez, 2015. Boletim técnico.

RIBAS, C. C. C; FONSECA, R. C. V. MANUAL DE METODOLOGIA OPET. Curitiba, 2008. Disponível em: 〈https://www.opet.com.br/storage/app/media/MANUAL_DE_MET_Jun_2011.pdf〉. Acesso em 18 out. 2018.

RODRIGUES, M. A. S; SALES, J. C. A madeira e suas patologias estudo de caso: IGREJA NOSSA SENHORA DAS MERCÊS-ITAPIPOCA CERARA. João Pessoa, PB. Anais do IX Congresso internacional sobre patologia e recuperação de estruturas. CINPAR, 2013.

SABATINI, L. B; et al. NOTAS DE AULA: patologias em revestimentos verticais. set./97.

SANTOS, F. B. Patologia das construções: uma especialidade na engenharia civil. 174ª ed. Set. 2011. Disponível em :<http://techne17.pini.com.br/engenharia-civil/174/patologia- das-construcoes-uma-especialidade-na-engenhariacivil-285892-1.aspx > Acessado em 12 out. 2018.

SILVA, A. P; JONOV, C. M. P. Patologia das construções. 2011. Curso de especialização em construção civil. Universidade Federal de Minas Gerais, minas gerais. 2011. Disponível em: <http://www.demc.ufmg.br/adriano/Patologia\%20das\%20Construcoes.pdf>. Acesso em 05 out. 2018.

SOUZA, V. C; RIPPER, T. Patologia, recuperação e reforço de estruturas de concreto. $1^{\circ}$. ed. São Paulo: Pini,1998.

TUTIKIAN, B; PACHECO, M. Inspeção, diagnóstico e prognóstico na construção civil. Mérida-México. ALCONPAT Brasil. n. 1, mar. 2013. Boletim técnico.

UNIFACEMA. Elaboração de trabalhos acadêmico-científicos: manual de orientação. Caxias, MA: UNIFACEMA, 2018.

VAlente, A. P. V; SILVA, A. P; CALIXTO, J. M. F. Análise dos processos de recuperação de patologias: trincas e impermeabilização. Belo horizonte: Revista Construindo v1.n 2 p. 7-11. jul./dez. 2009.

VITÓRIO, A. Fundamentos da patologia das estruturas nas perícias de engenharia.

Disponível em:

<http://vitorioemelo.com.br/publicacoes/Fundamentos_Patologia_Estruturas_Pericias_Engen haria.pdf>. Acesso em: 20 nov. 2018.

http://www.estacoesferroviarias.com.br/ma-pi/caxias.htm 